\title{
Endoscopic pancreatic and biliary manometry in pancreatic, biliary, and papillary disease, and after endoscopic sphincterotomy and surgical sphincteroplasty
}

\author{
J A GREGG AND D L CARR-LOCKE
}

From the New England Baptist Hospital, Boston, Mass, USA and Leicester Royal Infirmary, Leicester

SUMMARY Endoscopic manometry was used to measure pancreatic duct, common bile duct, pancreatic duct sphincter and bile duct sphincter pressures in 43 healthy volunteers and 162 patients with a variety of papillary, pancreatic and biliary disorders. Common bile duct pressure was significantly raised after cholecystectomy, with common bile duct stones and papillary stenosis but pancreatic duct pressure only in papillary stenosis. After endoscopic sphincterotomy mean common bile duct pressure fell from 11.2 to $1 \cdot 1 \mathrm{mmHg}$ and pancreatic duct pressure from 18.0 to $11.2 \mathrm{mmHg}$. Distinct pancreatic duct sphincter and bile duct sphincter zones were identified as phasic pressures of 3-12 waves/minute on pull-through from pancreatic duct and common bile duct to duodenum. Pancreatic duct sphincter pressures were higher with common bile duct stones and stenosis whereas bile duct sphincter pressures were higher in pancreatitis and stenosis. Bile duct sphincter activity was present in $60 \%$ of patients after surgical sphincteroplasty but $21 \%$ of patients after endoscopic sphincterotomy. Endoscopic manometry facilitated the diagnosis of papillary stenosis, has allowed study of papillary pathophysiology and has shown a functional inter-relationship between the two sphincteric zones.

The role of the sphincter of Oddi in the pathogenesis of pancreatic and biliary diseases and their effects upon it have received little attention in human studies. Various pathophysiological mechanisms have been suggested to implicate dysfunction of the pancreatic-biliary sphincter apparatus in gall stone formation, ${ }^{12}$ pancreatitis $^{34}$ and the postcholecystectomy syndrome $e^{5-7}$ but direct study of this area became possible only recently with the advent of endoscopic manometry. ${ }^{8-12}$ Previously the sphincter of Oddi was accessible only indirectly for manometric study by the use of intra-operative or postoperative bile duct pressure-flow systems. ${ }^{13}$ The diagnosis of papillary stenosis remains controversial despite an increasing literature on the subject since the 1950s. ${ }^{5714-18}$ Radiological criteria based on ERCP studies ${ }^{19-21}$ have helped delineate this entity further but endoscopic manometric measurements $^{10} 112122$ would seem a promising method for

Address for correspondence: Dr D L Carr-Locke, Gastroenterology Unit. Leicester Royal Infirmary, Leicester LE1 5WW.

Received for publication 10 February 1984 accurate diagnosis.

Surgical and endoscopic operations on the sphincter of Oddi are frequently used in the management of choledocholithiasis and papillary stenosis. ${ }^{18}{ }^{23-29}$ Little information is available on the effects of these procedures on the biliary-pancreatic sphincter apparatus and recent studies using endoscopic manometry ${ }^{10-12}$ 30-32 have concentrated on measurements of common bile duct pressure ${ }^{10-12}$ ${ }^{30-32}$ and bile duct sphincter zone phasic activity. ${ }^{30-32}$ Numbers of patients studied before and after endoscopic sphincterotomy have been small and only one study reports changes in pancreatic duct pressure $^{31}$ but not pancreatic duct sphincter zone dynamics.

We have previously reported our results of endoscopic manometry in healthy volunteers ${ }^{33}$ and now report our findings in a group of patients asymptomatic after cholecystectomy and those with common bile duct stones, pancreatis, suspected papillary stenosis, and in patients after endoscopic sphincterotomy and surgical sphincteroplasty. 


\section{Methods}

PATIENTS

One hundred and sixty two patients gave written consent to undergo endoscopic manometry and their results were compared with 43 healthy volunteers (Group N) amalgamated from previous studies. ${ }^{35-35}$ These were 19 men and 24 women, aged 19 to 51 years, selected on the basis of an absence of a history of biliary, pancreatic or any other gastrointestinal or other disease, pregnancy, use of any regular medication or an alcohol consumption greater than 30 grams per day. The protocol was approved by the New England Baptist Hospital clinical investigation committee. Patients were divided into eight groups. (1) Group PC consisted of four patients, aged 25 to 75 years, asymptomatic after cholecystectomy in whom no papillary, biliary or pancreatic disorders were suspected or found. (2) Group CDS consisted of 13 patients, aged 43 to 86 years, with common bile duct stones of whom 10 had had a previous cholecystectomy. In none was there clinical, biochemical or radiological evidence of coexistent pancreatic disease. (3) Group P consisted of 12 patients, aged 23 to 75 years with acute or chronic relapsing pancreatitis documented on the basis of clinical, biochemical, ultrasonographic, radiological and secretory tests. In seven, pancreatitis was alcohol related and six had had a previous cholecystectomy. None was found to have an abnormal papilla during endoscopic cannulation and none had biliary calculi at the time of examination. (4) Group S consisted of 44 patients with a history of recurrent or constant biliary or pancreatic type pain considered to have papillary stenosis. This diagnosis was based on calibration of the papilla using a standard $1.7 \mathrm{~mm}$ diameter ERCP cannula, dilatation of the common bile duct of greater than $10 \mathrm{~mm}$ in the postcholecystectomy state and a pancreatic duct diameter of $5 \mathrm{~mm}$ or greater in the head of the pancreas with delayed drainage beyond 30 minutes of contrast medium from the ductal system after ERCP. Thirty eight patients in this group had had a previous cholecystectomy. (5) Group SPD consisted of five patients found to have stenosis of the pancreatic duct orifice at ERCP of whom four had had a previous surgical choledochal sphincteroplasty and one endoscopic sphincterotomy. Three patients had also had a previous failed distal pancreatic drainage procedure. (6) Group PSS consisted of 20 patients who had had a previous transduodenal surgical sphincteroplasty of the choledochal sphincter after cholecystectomy in whom symptoms had continued or returned suggesting pancreatic and/or biliary pain and had led to referral for ERCP. None had common bile duct stones. (7) Group PES consisted of 56 patients studied after endoscopic sphincterotomy of the choledochal sphincter performed for choledocholithiasis or papillary stenosis. (8) Group ESPD consisted of eight patients on whom endoscopic sphincterotomy of the pancreatic duct orifice was performed for stenosis. Six had had a previous surgical choledochal sphincteroplasty, two an endoscopic choledochal sphincterotomy and three had had a failed distal pancreatic drainage operation. All had severe episodic or continuous pancreatic-type pain before endoscopic sphincterotomy.

Endoscopic manometry was performed at the same session as, but immediately before ERCP as previously described.$^{33}$ After an eight hour fast the subject lay comfortably in the left lateral or semiprone position after local pharyngeal anaesthesia had been administered by benzocaine spray. Sedation was then induced with intravenous diazepam and no other drugs were given until manometry recordings had been completed. Dudoenoscopy was performed with a Fujinon DUOX duodenoscope, and the manometry catheter, a modified Fujinon ERCP catheter with a $1.2 \mathrm{~mm}$ diameter side hole $4 \mathrm{~mm}$ from its sealed tip, was passed through the instrument channel into the duodenum with the transducer level with the subject's abdomen. Using a perfusion rate of 0.62 $\mathrm{ml} / \mathrm{min}$ of $0.9 \%$ saline delivered by a Harvard 2681 infusion pump, an initial duodenal pressure was recorded. The papilla was then cannulated and the catheter deeply inserted into a duct. Aspiration of bile or pancreatic juice together with fluoroscopic verification allowed identification of the duct cannulated. Ductal pressures were then measured and the catheter then slowly withdrawn until a phasic high pressure zone was located on pullthrough. A station recording was made and the distance of this zone from the papillary orifice could be read from the catheter markings. Duodenal pressure was again recorded after each pull-through manoeuvre as this was used as a zero reference for each recording. Ductal and duodenal pressures were read directly from each tracing and a mean of the peak and trough phasic pressures calculated from the phasic zone activity as previously described. ${ }^{33}$ Wave amplitude, frequency and duration were also calculated and groups were compared statistically using the Student's $t$ test for unpaired data.

\section{Results}

The results of ductal pressure measurements are shown in Tables 1 and 2. Pancreatic duct (PD) pressure was not significantly different from normal 
Table 1 Ductal and phasic sphincter pressures for normal subjects and patient groups

\begin{tabular}{|c|c|c|c|c|c|c|}
\hline \multirow[b]{2}{*}{ Patient group } & \multirow[b]{2}{*}{ Pancreatic duct } & \multicolumn{2}{|c|}{ Pancreatic duct sphincter } & \multirow[b]{2}{*}{ Common bile duct } & \multicolumn{2}{|c|}{ Bile duct sphincter } \\
\hline & & Peak & Trough & & Peak & Trough \\
\hline$N(43)$ & $10 \cdot 7 \pm 3.9$ & $47 \cdot 2 \pm 8 \cdot 4$ & $15 \cdot 9 \pm 6 \cdot 6$ & $51 \cdot 2 \pm 6 \cdot 7$ & $51 \cdot 2 \pm 6 \cdot 7$ & $13 \cdot 4 \pm 6 \cdot 2$ \\
\hline PC (4) & $14 \cdot 0 \pm 4 \cdot 0$ & $54 \cdot 4 \pm 9 \cdot 1$ & $11 \cdot 0 \pm 7 \cdot 1$ & $6 \cdot 0 \pm 1 \cdot 8 \ddagger$ & $44 \cdot 3 \pm 6 \cdot 7$ & $13 \cdot 1 \pm 8 \cdot 0$ \\
\hline $\operatorname{CDS}(13)$ & $10 \cdot 0 \pm 2 \cdot 0$ & $67 \cdot 3 \pm 22 \cdot 7 \ddagger$ & $30 \cdot 3 \pm 15 \cdot 7 \dagger$ & $14 \cdot 2 \pm 5 \cdot 8 \ddagger$ & $46 \cdot 6 \pm 15 \cdot 6$ & $16 \cdot 5 \pm 9 \cdot 3$ \\
\hline$P(12)$ & $15 \cdot 4 \pm 7 \cdot 9$ & $60 \cdot 4 \pm 25 \cdot 2^{*}$ & $20 \cdot 1 \pm 10 \cdot 9$ & $7 \cdot 1 \pm 6 \cdot 5$ & $66 \cdot 1 \pm 17 \cdot 2 \dagger$ & $17.8 \pm 8.8$ \\
\hline S (44) & $18 \cdot 9 \pm 6 \cdot 8 \ddagger$ & $72 \cdot 5 \pm 21 \cdot 1 \ddagger$ & $23 \cdot 5 \pm 11 \cdot 1 \ddagger$ & $9 \cdot 9 \pm 4 \cdot 0 \ddagger$ & $67 \cdot 1 \pm 11 \cdot 9 \ddagger$ & $26 \cdot 4 \pm 12 \cdot 4 \ddagger$ \\
\hline
\end{tabular}

Given in $\mathrm{mmHg}$ as mean $\pm 1 \mathrm{SD}$. Significant differences from normal values are given by ${ }^{*} \mathrm{p}<0 \cdot 01, \dagger \mathrm{p}<0.005, \ddagger \mathrm{p}<0.001$.

$\mathbf{N}=$ normal. $\mathbf{P C}=$ postcholecyst. $\mathrm{CDS}=$ common duct stone. $\mathrm{P}=$ pancreatitis. $\mathrm{S}=$ papillary stenosis.

in asymptomatic postcholecystectomy subjects (PC), patients with common duct stones (CDS) and patients with pancreatitis $(\mathrm{P})$ but was raised in papillary stenosis $(\mathrm{S})$, stenosis of the pancreatic duct orifice (SPD) and in patients after surgical sphincteroplasty (PSS). Common bile duct (CBD) pressure was not significantly different from normal in Groups $\mathrm{P}$ and PSS but values in Groups PC, S and CDS were significantly raised. In nine patients $(45 \%)$ of Group PSS there ws no CBD-duodenal gradient present. Common bile duct pressure was also significantly raised in Groups CDS and S compared with asymptomatic postcholecystectomy subjects. Pancreatic duct pressure was higher than common bile duct pressure in all groups except those with common bile duct stones where the reverse was found.

The effect of endoscopic sphincterotomy is shown in Figures 1 and 2. Pancreatic duct pressure fell from $18.0 \pm 7.0$ to $11.2 \pm 5.0 \mathrm{mmgHg}(\mathrm{p}<0.001)$ and common bile duct pressure fell from $11.2 \pm 4.9$ to $1.1 \pm 1.1 \mathrm{mmHg}(\mathrm{p}<0.001)$ with 39 subjects $(70 \%)$ showing no common bile duct-duodenal pressure gradient. In the small group of patients undergoing sphincterotomy of the pancreatic duct orifice
(ESPD) pancreatic duct pressure fell significantly from $22.4 \pm 7.6$ to $8 \cdot 0 \pm 6.0 \mathrm{mmHg}(\mathrm{p}<0.005)$.

Distinct zones of high phasic pressures with a mean frequency of six waves/min (range 3-12 waves/min) and a mean duration of seven seconds (6.2-8.4 seconds) were found on pull-through from pancreatic duct and common bile duct towards the duodenum at a distance of $4-5 \mathrm{~mm}$ from the papilla. These zones were designated pancreatic duct sphincter and bile duct sphincter zones respectively as we have previously discussed ${ }^{33}$ and examples are shown in Figure 3. Peak and trough pancreatic duct sphincter and bile duct sphincter pressures are shown in Tables 1 and 2. For pancreatic duct sphincter pressures there was no significant difference from normal in Groups PC, PES, and PSS but a significant rise was found in Groups $P$, CDS, S, and SPD. Significant falls in pancreatic duct sphincter pressures occurred after endoscopic sphincterotomy (Fig. 1) and in the eight subjects undergoing pancreatic duct orifice sphincterotomy (ESPD). Two subsequently showed no phasic activity and in the remaining six there were significant falls in pancreatic duct sphincter pressures (Fig. 1).

Table 2 Ductal and phasic sphincter pressures for normal subjects and patient groups

\begin{tabular}{|c|c|c|c|c|c|c|}
\hline \multirow[b]{2}{*}{ Patient group } & \multirow[b]{2}{*}{ Pancreatic duct } & \multicolumn{2}{|c|}{ Pancreatic duct sphincter } & \multirow[b]{2}{*}{ Common bile duct } & \multicolumn{2}{|l|}{ Bile duct sphincter } \\
\hline & & Peak & Trough & & Peak & Trough \\
\hline$N(43)$ & $10 \cdot 7 \pm 3.9$ & $47 \cdot 2 \pm 8 \cdot 4$ & $15 \cdot 9 \pm 6 \cdot 6$ & $2 \cdot 0 \pm 1 \cdot 7$ & $51 \cdot 2 \pm 6 \cdot 7$ & $13 \cdot 4 \pm 6 \cdot 2$ \\
\hline SPD (5) & $22 \cdot 4 \pm 10 \cdot 9 \ddagger$ & $98 \cdot 3 \pm 15 \cdot 7 \ddagger$ & $25 \cdot 2 \pm 9 \cdot 2^{*}$ & - & - & - \\
\hline PSS (20) & $17 \cdot 0 \pm 7 \cdot 5 \ddagger$ & $56 \cdot 5 \pm 24 \cdot 7$ & $13 \cdot 0 \pm 8 \cdot 5$ & $2 \cdot 7 \pm 2 \cdot 6(11)$ & $37 \cdot 0 \pm 12 \cdot 3 \ddagger(12)$ & $6 \cdot 5 \pm 4 \cdot 4 \ddagger(12)$ \\
\hline PES (56) & $11 \cdot 2 \pm 5 \cdot 0$ & $55 \cdot 0 \pm 18 \cdot 0$ & $16 \cdot 9 \pm 8 \cdot 5$ & $1 \cdot 1 \pm 1 \cdot 1(17)$ & $31 \cdot 2 \pm 9 \cdot 8 \ddagger(12)$ & $7 \cdot 2 \pm 4 \cdot 0 \ddagger(12)$ \\
\hline ESPD (8) & $8 \cdot 0 \pm 6.0$ & $39 \cdot 2 \pm 8 \cdot 8 \ddagger(6)$ & $9 \cdot 6 \pm 7 \cdot 4^{*}(6)$ & - & - & - \\
\hline
\end{tabular}

Given in $\mathrm{mmHg}$ as mean $\pm 1 \mathrm{SD}$. Significant differences from normal values given by ${ }^{*} \mathrm{p} 0.01,+\mathrm{p} 0.005, \ddagger \mathrm{p} 0.001$.

Number of subjects in parentheses.

$\mathrm{N}=$ normal. $\mathrm{SPD}=$ pancreatic duct stenosis. $\mathrm{PSS}=$ surgical sphincteroplasty. $\mathrm{PES}=$ endoscopic sphincterotomy. ESPD $=$ pancreatic

sphincterotomy. 


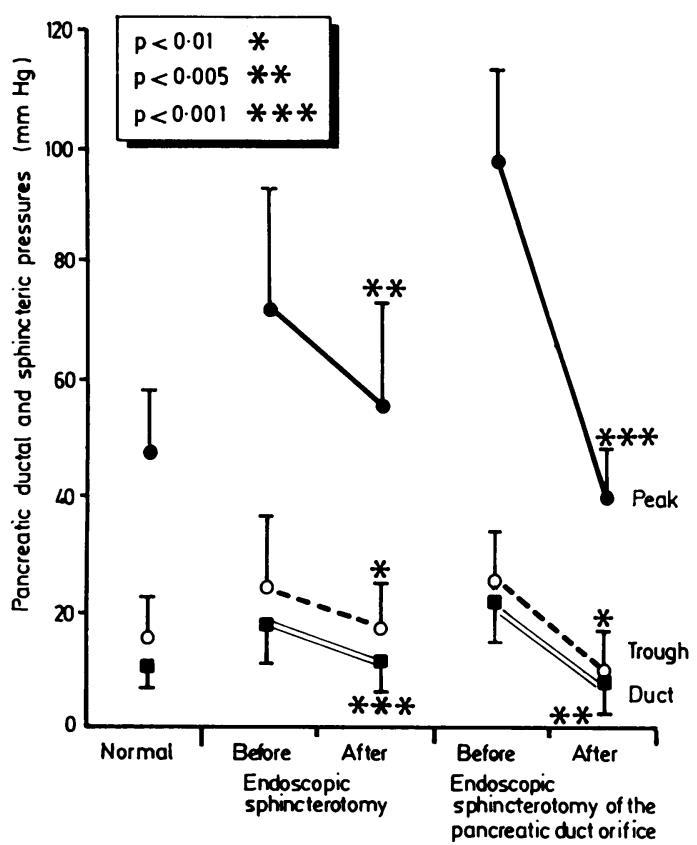

Fig. 1 Pancreatic duct and pancreatic duct sphincter pressures in 43 healthy volunteers (normal), 56 patients before and after endoscopic sphincterotomy and 8 patients before and after endoscopic sphincterotomy of the pancreatic duct orifice. Values are mean $\pm 1 S D$ pancreatic duct pressure, phasic sphincter pressures. Statistical differences from pre-endoscopic sphincterotomy measurements are shown by*.

Peak and trough bile duct sphincter pressure results are shown in Tables 1 and 2. There was no significant difference from normal in Groups PC and CDS but a significant rise was found in Groups $P$ and S. After surgical sphincteroplasty 12 of the 20 patients showed significantly lower pressures than normal and in the other eight of this group no

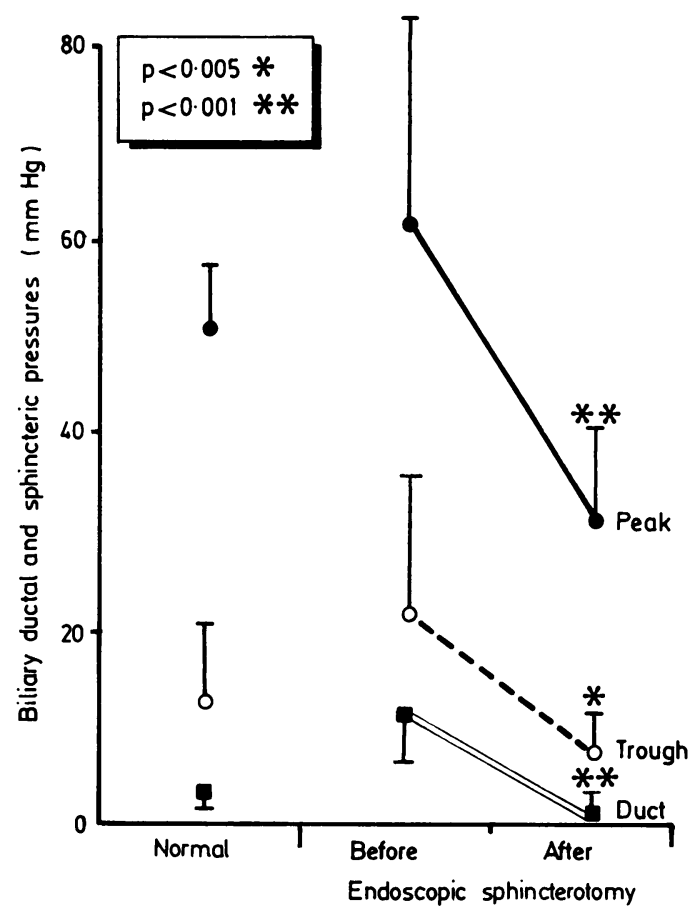

Fig. 2 Common bile duct and bile duct sphincter pressures in 43 healthy volunteers (normal) and in 56 patients before and after endoscopic sphincterotomy common bile duct pressure and phasic sphincter pressures. Values are mean \pm ISD. Stastical differences from pre-sphincterotomy values are shown by *.

detectable phasic activity was present. After endoscopic sphincterotomy no detectable bile duct sphincter activity was present in 44 of the 56 subjects and in the remaining 12 pressures were significantly lower than presphincterotomy values and normal subjects.

In patients with a diagnosis of papillary stenosis
Fig. 3 Endoscopic manometry recordings in same patient showing (a) common bile duct $(C B D)$ pressure, duodenal pressure $(D)$ and pull-through phasic activity (bile duct sphincter) with slower wave frequency than in (b) showing pancreatic duct $(P D)$ pressure and pull-through phasic activity (Pancreatic duct sphincter).

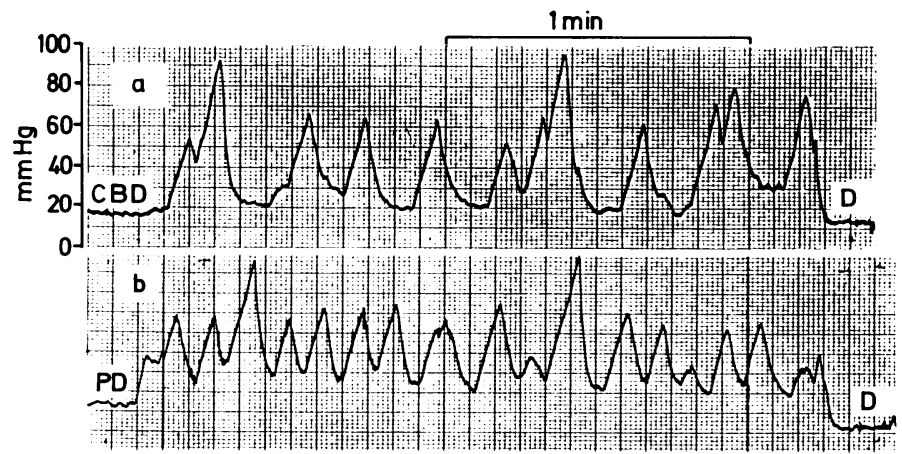


two patterns of pull-through recordings were obtained as shown in Figure 4. One was characterised by high amplitude waves with raised peak and trough pressures together with a raised ductal pressure and the other pattern exhibited a high pressure zone extending over $2-3 \mathrm{~mm}$ with little or no phasic activity at the expected site together with a raised ductal pressure.

Table 3 shows the percentage of patients in Groups CDS, $P$ and $S$ with ductal and phasic pressure values greater than $2 \mathrm{SD}$ above the normal mean. This revealed that $85 \%$ of patients with common bile duct stones and $75 \%$ with papillary stenosis had common bile duct pressures greater than $9.6 \mathrm{mmHg}$. In addition, $40 \%$ of patients with papillary stenosis had pancreatic duct pressures above the limit of $18.5 \mathrm{mmHg}$ and two-thirds of this group had raised peak pancreatic duct sphincter and peak bile duct sphincter pressures above the normal limits. Table 4 expresses the same data as the percentage in each group with between one and six abnormal values based on the above mentioned limits. In patients with common bile duct stones the majority had only one abnormal value, in pancreatitis five patients $(42 \%)$ had no abnormal value but in papillary stenosis the majority of patients had two or more abnormal values.

The differences between a ductal and trough phasic sphincter pressures were $7 \cdot 3 \pm 4.9$ and $12.0 \pm 5.7 \mathrm{mmHg}$ in normal subjects for pull-through recordings from pancreatic duct and common bile duct respectively. Values in patient groups were not significantly different except those with papillary stenosis where this difference was significantly raised to $13.1 \pm 10.3 \mathrm{mmHg}(\mathrm{p}<0.02)$ and $18.6 \pm 13.3$ $\mathrm{mmHg}(\mathrm{p}<0 \cdot 01)$ for pancreatic duct and common bile duct recordings respectively.

\section{Discussion}

Despite detailed anatomical descriptions of the muscle fibres associated with the terminal parts of the common bile duct and pancreatic duct in man and many other species over the last century ${ }^{36} 37$ there is still debate concerning the functional activity of these sphincteric structures in $\operatorname{man}^{21} 3738$ and little is known of the pathophysiological changes which may take place in this area in patients with biliary and pancreatic disease. Endoscopic manometry has been used by a number of groups to investigate different disease states with varying results $^{10-12} 22$ 30-32 39-42 and some groups have also attempted to provide diagnostic criteria for papillary stenosis. 10112239

$\mathrm{We}^{33-35}$ and others ${ }^{10-12} 30-324043$ have shown common bile duct-duodenal and pancreatic ductduodenal pressure gradients and phasic pressures on pull-through from common bile duct to duodenum $^{30}{ }^{33-35} 40-43$ which, we believe, represent components of the sphincter of Oddi. Further evidence comes from the results in this and other studies showing a fall in the common bile duct-
Fig. 4 Endoscopic manometry recordings from (a) normal subject showing duodenal pressure $(D)$ and bile duct pull-through phasic activity (bile duct sphincter) with small waves simultaneous with respiration $(R),(b)$ patient with papillary stenosis after cholecystectomy showing raised common bile duct (CBD) and phasic pressures, (c) patient with papillary stenosis following cholecystectomy showing high plateau pressure replacing phasic activity in presumed stenotic segment $(S S)$, and $(d)$ patient shown in (c) after endoscopic sphincterotomy with loss of all phasic activity and $C B D$ duodenal pressure gradient.

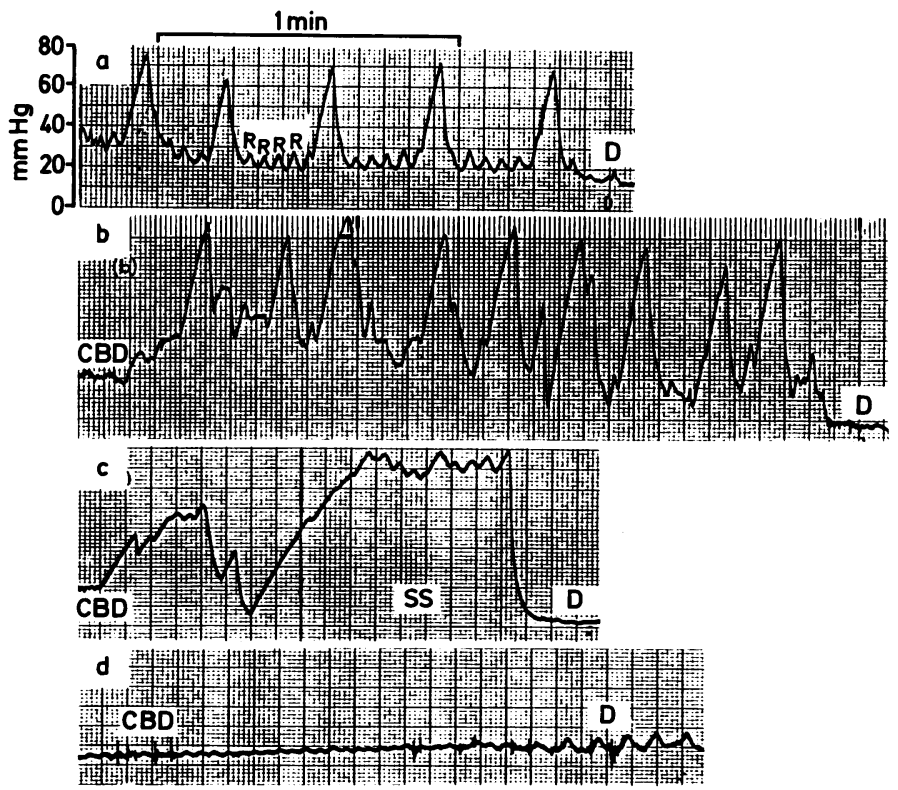


Table 3 Percentage of patients in three disease groups

\begin{tabular}{|c|c|c|c|c|}
\hline \multirow[b]{2}{*}{ Pressures } & \multirow{2}{*}{$\begin{array}{l}\text { Group } N, \text { mean } \pm 2 S D \\
m m H g(43)\end{array}$} & \multicolumn{3}{|c|}{$\%$ greater than value in first column } \\
\hline & & Group CDS (13) & Group P (12) & Group S (44) \\
\hline Pancreatic duct & $18 \cdot 5$ & 0 & $8 \cdot 3$ & 40 \\
\hline \multicolumn{5}{|c|}{ Pancreatic duct sphincter } \\
\hline Trough & $29 \cdot 2$ & $15 \cdot 4$ & 25 & $37 \cdot 9$ \\
\hline Peak & $63 \cdot 9$ & $15 \cdot 4$ & 25 & $65 \cdot 5$ \\
\hline Common bile duct & $9 \cdot 6^{*}$ & 85 & 17 & 75 \\
\hline \multicolumn{5}{|l|}{ Bile duct sphincter } \\
\hline Trough & $25 \cdot 8$ & $7 \cdot 7$ & 0 & $44 \cdot 8$ \\
\hline Peak & $64 \cdot 5$ & $23 \cdot 1$ & $33 \cdot 3$ & $62 \cdot 1$ \\
\hline
\end{tabular}

(Number of patients in parentheses) with values above an arbitrary normal limit of mean $\pm 2 \mathrm{SD}$ from Normal.

* mean +2 SD from Postcholecyst.

duodenal gradient to near zero ${ }^{10-12} 30-32$ and abolition of phasic activity ${ }^{30}$ after endoscopic sphincterotomy. We have previously discussed our contention that a separate manometrically measurable pancreatic duct sphincter zone exists on pull-through from pancreatic duct to duodenum ${ }^{33}$ which is still present after destruction of the choledochal sphincter. The falls in pancreatic duct and pancreatic duct sphincter pressures after sphincterotomy imply a functional interdependence between the bile duct sphincter and pancreatic duct sphincter zones as suggested by the anatomical inter-relationships of Boyden's sphincter choledochus and sphincter pancreaticus. ${ }^{37}$

A consistent finding throughout studies in which pancreatic duct and common bile duct pressures have been measured in the same individuals ${ }^{1022} 314044-46$ is that pancreatic duct pressure is higher than common bile duct pressure and we have had similar results in studies of normal subjects. ${ }^{33-35}$ This may explain the mechanism underlying a recent report of pancreatic enzymes present in common bile duct bile. ${ }^{1}$ The difference was reversed in our patients with common bile duct

Table 4 Percentage of patients in three disease groups with none or 1-6 abnormal values based on the arbitrary limit shown in Table 1.

\begin{tabular}{lccc}
\hline & $\begin{array}{l}\text { Group } C D S, \\
\%(13)\end{array}$ & $\begin{array}{l}\text { Group } P, \\
\%(12)\end{array}$ & $\begin{array}{l}\text { Group } S, \\
\%(44)\end{array}$ \\
\hline No abnormal value & 0 & $41 \cdot 8$ & 0 \\
1 abnormal value & $69 \cdot 2$ & $16 \cdot 6$ & $18 \cdot 2$ \\
2 abnormal values & $15 \cdot 4$ & 25 & $29 \cdot 5$ \\
3 abnormal values & $7 \cdot 7$ & $8 \cdot 3$ & $27 \cdot 3$ \\
4 abnormal values & $7 \cdot 7$ & $8 \cdot 3$ & 11.4 \\
5 abnormal values & 0 & 0 & $6 \cdot 8$ \\
6 abnormal values & 0 & 0 & 6.8 \\
\hline
\end{tabular}

Number of patients in each group in parentheses. stones, a finding not supported by others, ${ }^{31}{ }^{40}$ and was due to the high common bile duct pressures compared with controls. This may be relevant to the mechanism of gall stone related acute pancreatitis ${ }^{3}$ but the mechanism of high common bile duct pressures in this situation is not known.

Our findings in patients with pancreatitis show rises of ductal and sphincteric pressures and there was no difference in values between alcohol related and non-alcohol related cases. The relevance of these findings to pathogenetic mechanisms of pancreatitis or the effects of pancreatitis on sphincter function are unknown but as some patients have values outside the proposed normal limits (Table 3) there may be a degree of sphincter dysfunction and outflow obstruction in a proportion.

Papillary stenosis seems well recognised in France, ${ }^{716}$ Germany, ${ }^{1120}$ some centres in USA $^{14}{ }^{15}$ 17-19 $_{22}$ and South America ${ }^{47}$ 48 but has appeared less frequently in the British literature. Despite well documented clinical and pathological literature on the subject, ${ }^{571011} 14-182325-2747-49$ the diagnosis may be difficult to make and many clinicians are reluctant to consider it. We have shown that the manometric characteristics of a group of patients selected on the radiological criteria above mentioned were significantly different from normal and no patient in this group had completely normal manometric results compared with $42 \%$ of patients with pancreatitis. Clearly patients with common bile duct stones can be distinguished by other means. We have subsequently used these criteria to select patients for endoscopic sphincterotomy with encouraging results to be reported elsewhere.

We conclude that endoscopic manometry provides a reliable method for studying the pathophysiology of disorders affecting the pancreatic and biliary sphincter mechanisms and has allowed us to establish additional criteria for the 
diagnosis of papillary stenosis. A functional interrelationship between the sphincteric zones of the terminal bile duct and pancreatic duct is suggested but the pancreatic duct sphincter can preserve its independent activity after complete incision of the choledochal sphincter.

This work was supported by grants from the Katherine Gavriluk and Sara Jordan Funds, New England Baptist Hospital, Boston, Massachusetts and $\mathrm{Dr}$ Carr-Locke is in receipt of grants from the Wellcome Research Travel Fund, London, the Leicester Area Health Authority and the P and C Hickinbotham Trust, Leicester, England. We are grateful to Elizabeth Knight RN and Louise Jackson RN who assisted during endoscopic manometry and Fujinon Optical Inc. New York, USA for help with the equipment.

\section{References}

1 Anderson MC, Hauman RL, Suriyapa C, Schiller WR. Pancreatic enzyme levels in bile of patients with extra hepatic biliary tract disease. Am J Surg 1979; 137: 301-6.

2 Hauman RL, Gramatica L, Anderson MC. Effect of specific pancreatic enzymes on the gallbladder. Surg Forum 1970; 21: 388-9.

3 White TT. The part that the sphincter of Oddi plays in the etiology of pancreatitis. In: The sphincter of Oddi. Proc 3rd Gastroenterol Symp, Nice 1976, Basel: Karger, 1977: 175-9.

4 Mouiel J, Bourgeon R, Chauvin P, Bertrand JC, Giaume F, Rey JF. Pancreatitis due to obstructiuon of Oddi's sphincter. In: The sphincter of Oddi. Proc 3rd Gastroenterol Symp, Nice 1976, Basel: Karger, 1977: 163-74.

5 Tondelli P, Gyr K, Stalder GA, Allgower M. The post cholecystectomy syndrome. Clin Gastroenterol 1979; 8: 487-505.

6 Schein CJ. Post cholecystectomy syndromes. A clinical approach to etiology, diagnosis and management. New York: Harper and Row, 1978: 199-27.

7 Delmont J. An attempt to collate. In: The sphincter of Oddi. Proc 3rd Gastroenterol Symp, Nice 1976. Basel: Karger, 1977: 240-55.

8 Vondrasek P, Eberhard G, Classen M. Endoscopic semi-conductor manometry. Int J Med 1974; 3: 188-92.

9 Nebel OT. Manometric evaluation of the papilla of Vater. Gastrointest Endosc 1975; 21: 126-8.

10 Rosch W, Koch H, Demling L. Manometric studies during ERCP and endoscopic papillotomy. Endoscopy 1976; 8: 30-3.

11 Hagenmuller F, Ossenberg FW, Classen M. Duodenoscopic manometry of the common bile duct. In: The sphincter of Oddi. Proc 3rd Gastroenterol Symp, Nice
1976. Basel: Karger, 1977: 72-6.

12 Geenen JE, Hogan WJ, Shaffer RD, Stewart ET, Dodds WJ, Arndorder RC. Endoscopic electrosurgical papillotomy and manometry in biliary tract disease. JAMA 1977; 237: 2075-8.

13 Wong $\mathrm{HN}$, Frey $\mathrm{CF}$, Gagic NM. Intraoperative common duct pressure and flow measurements. $\mathrm{Am} \mathrm{J}$ Surg 1980; 139: 691-5.

14 Cattell RB, Colcock BP. Fibrosis of the sphincter of Oddi. Ann Surg 1953; 137: 797-806.

15 Acosta JM, Civantos F, Nardi GL, Castleman B. Fibrosis of the papilla of Vater. Surg Gynecol Obstet 1967; 124: 787-94.

16 Yvergneaux JP, Bauwens E, Van Outryvie L, Yvergneaux E. Benign stenosis of the papilla of Vater. Acta Chir Belge 1977; 76: 523-32.

17 Gregg JA, Clark G, Barr C, McCartney A, Milano A, Volcjak C. Post cholecystectomy syndrome and its association with ampullary stenosis. Am J Surg 1980; 139: $374-8$

18 Siegel JH. Endoscopic management of choledocholithiasis and papillary stenosis. Surg Gynecol Obstet 1979; 148: 747-52.

19 Zimmon DS, Ferrara TP and Clemetts AR. Radiology of papilla of Vater stenosis. Gastrointest Radiol 1978; 3: 343-8.

20 Anacker H, Weiss HD and Kramann B. Endoscopic retrograde pancreatico-cholangiography in chronic diseases of the pancreas and papillary stenosis. Gastrointest Radiol 1978; 3: 325-34.

21 Delmont J. An attempt to collate. In: The sphincter of Oddi. Proceedings of the Third Gastrointestinal Symposium, Nice, 1976. Basel: Karger, 1977: 240-55.

22 Bar-Meir S, Geenen JE, Hogan WJ, Dodds WJ, Stewart ET, Arndorfer RC. Biliary and pancreatic duct pressures measured by ERCP manometry in patients with suspected papillary stenosis. Dig Dis Sci 1979; 24: 209-13.

23 Geenen JE, Vennes JA, Silvis SE. Resume of a seminar on endoscopic retrograde sphincterotomy. Gastrointest Endosc 1981; 27: 31-8.

24 Cotton PB. Non-operative removal of bile duct stones by duodenoscopic sphincterotomy. Br J Surg 1980; 67: $1-5$.

25 Nakajima M, Kizu M, Akasaka Y and Kawai K. Five years experience of endoscopic sphincterotomy in Japan. Endoscopy 1979; 2: 138-41.

26 Reiter JJ, Bayer HP, Mennicken C, Manigold BC. Results of endoscopic papillotomy. A collective experience from nine endoscopic centres in West Germany. World J Surg 1978; 2: 505-11.

27 Safrany L. Endoscopic treatment of biliary tract disorders. Acta Gastroenterol Belg 1978; 41: 659-66.

28 Classen M, Ossenberg FW. Non-surgical removal of common bile duct stones. Gut 1977; 18: 760-9.

29 Jones SA. Sphincteroplasty (not sphincterotomy) in the treatment of biliary tract disease. Surg Clin N Am 1973; 53: $1123-37$.

30 Funch-Jensen $\mathrm{P}$, Csendes A, Kruse A, Oster MJ, Amdrup E. Common bile duct and Oddi sphincter pressure before and after endoscopic papillotomy in patients with common bile duct stones. Ann Surg 1979; 
190: $176-8$.

31 Tanaka M, Ikeda S, Nakayama F. Non-operative measurement of pancreatic and common bile duct pressures with a micro-transducer catheter and effects of duodenoscopic sphincterotomy. Dig Dis Sci 1981; 26: $545-52$.

32 Mavrelis P, Geenen JE, Hogan WJ et al. Long-term effects of endoscopic sphincterotomy on sphincter of Oddi structure and motor function. Gastroenterology 1981; 80: 1225.

33 Carr-Locke DL, Gregg JA. Endoscopic manometry of pancreatic and biliary sphincter zones in man. Basal results in healthy volunteers. Dig Dis Sci 1981; 26: $7-15$.

34 Carr-Locke DL, Gregg JA, Chey WY. Effects of exogenous secretin on pancreatic and biliary ductal and sphincteric pressures in man demonstrated by endoscopic manometry and correlation with plasma secretin levels. Dig Dis Sci. 1984 (in press).

35 Carr-Locke DL, Gregg JA, Aoki TT. Effects of exogenous glucagon on pancreatic and biliary ductal and sphincteric pressures in man demonstrated by endoscopic manometry and correlation with plasma glucagon. Dig Dis Sci 1983; 28: 312-20.

36 Boyden EA. The sphincter of Oddi in man and certain representative mammals. Surgery 1937; 1: 25-37.

37 Boyden EA. The anatomy of the choledochoduodenal junction in man. Surg Gynecol Obstet 1957; 104: 641-52.

38 Didio LJA, Anderson MC. The sphincters of the digestive systems. Anatomical, functional and surgical consideration. Baltimore: Williams and Wilkins; 1968: 128-51.

39 Carr-Locke DL, Gregg JA. Endoscopic manometry of biliary and pancreatic sphincters. Findings in biliary and pancreatic disease and after sphincter surgery. Am
J Gastroenterol 1979; 72: 333.

40 Csendes A, Cruse A, Funch-Jensen P, Oster MJ, Ornsholt J, Andrup E. Pressure measurements in the biliary and pancreatic duct systems in controls and in patients with gallstones, previous cholecystectomy, or common bile duct stones. Gastroenterology 1979; 77: 1203-10.

41 Bradley VD, Nebel OT. Clinical evaluation of sphincter of Oddi manometry. Gastrointest Endosc 1977; 24: 27-9.

42 Toouli J, Geenen JE, Hogan WJ, Dodds WJ, Arndorfer RC. Sphincter of Oddi motor activity. Differences between patients with common bile duct stones and controls. Gastroenterology 1981; 80: 1304.

43 Geenen JE, Hogan WJ, Dodds WJ, Stewart ER, Arndorfer RC. Intra luminal pressure recording from the human sphincter of Oddi. Gastroenterology 1980; 78: $317-24$.

44 Geenen JE, Hogan WJ. Endoscopic access to the papilla of Vater. Endoscopy 1980; suppl: 47-56.

45 Weiss HD, Kramann B Wuttke V, Anacker H. Der Basisdruck im ductus pancreaticus und ductus choledochus. Med Klin 1977; 72: 519-23.

46 Anderson MC, Hagstrom WJ. A comparison of pancreatic and biliary pressures recorded simultaneously in man. Can J Surg 1962; 5: 461-70.

47 DelValle D, Donovan R. Coledoco-Odditis retractil cronica. Concepto Clinico Y Quirurgico. Archarg Enf Am Dig Nud 1926; 4: 1-10.

48 Paulino F, Cavalcanti A. Biopsy of the ampulla of Vater for demonstration of organic stenosis. Surgery 1960; 48: 698-705.

49 Logiudice JA, Geenen JE, Hogan WJ, Dodds WJ. Efficacy of the morphine-Prostigmin test for evaluating patients with suspected papillary stenosis. Dig Dis Sci 1979; 24: 455-8. 